\title{
ANISOPTERA (ODONATA) DA CHAPADA DIAMANTINA: RIQUEZA E MORFOLOGIA
}

\author{
Luiza Burgos de Souza Leite1; \& Freddy Ruben Bravo Quijano²; \\ 1. Bolsista PIBIC/CNPq, Graduando em Bacharelado em Ciências Biológicas, Universidade Estadual de Feira de \\ Santana, e-mail: burgosluiza7@gmail.com \\ 2. Orientador, Departamento de Ciências Biológicas, Universidade Estadual de Feira de Santana, e-mail: \\ $\underline{\text { fbravo@uefs.br }}$
}

\section{PALAVRAS-CHAVE: Odonata; Morfologia; Sistemática.}

\section{INTRODUÇÃO}

Os integrantes da ordem Odonata são popularmente conhecidos como donzelinhas e libélulas(Costa et al., 2012) A Ordem atualmente está dividida em três subordens: Zygoptera, Anisozygoptera e Anisoptera (Tillyard \& Frazer,1938) é composta por cerca de 6.000 espécies (Shende \& Patil, 2013; Slater Museum, 2013), no entanto,é provável que o número de espécies possa alcançar as 10 mil.. Os indivíduos da subordem Anisoptera podem ser reconhecidos por apresentarem as bases das asas anteriores e posteriores diferentes que durante o pouso permanecem abertas (Souza et al., 2007). Desta subordem são conhecidas quatro famílias para o Brasil: Aeshnidae, Gomphidae, Corduliidae e Libellulidae. Há uma carência de estudos específicos da fauna de Odonata na Chapada Diamantina, assim, este projeto pretende apresentar resultados inéditos da fauna de Anisoptera (Odonata) de áreas de proteção ambiental, através de uma lista dos Odonatos que ocorrem nesta região.

\section{MATERIAL E MÉTODOS}

O presente trabalho foi realizado no Projeto Sempre Viva, uma área de preservação ambiental que conta com abundantes recursos hídricos, que está localizado no município de Mucugê (Parque Municipal de Mucugê, 2010), e em Igatú, distrito de Andaraí, ambos os locais de coleta estão situados no Nordeste baiano localizado na Serra do Sincorá cercado por numerosos rios (Funch, 1982) e são compreendidos por vasta área de mata, com características climáticas, topográficas e vegetação muito semelhantes. Para a captura dos animais foi utilizada rede entomológica (puçá), e, após captura, os exemplares de Anisoptera (Odonata) foram depositados ainda vivos em envelopes entomológicos de papel manteiga de acordo a metodologia de Costa et al. (2012). Para a identificação dos espécimes utilizou-se chaves de identificação disponíveis na literatura (Garrison et al., 2006). Para complementação da distribuição geográfica foram feitas consultas nos sites Neotropic Dragonfly (2012) e All Odonata.

\section{RESULTADOS E/OU DISCUSSÃO}

Foram coletados um total de 226 espécimes de Anisoptera (Odonata) em quatro coletas nas duas áreas do Parque Nacional da Chapada Diamantina, Mucugê e Igatú. A partir do material coletado foram identificadas 33 espécies pertencentes a 15 gêneros e duas famílias. A família Libellulidae foi a mais bem representada em termos de abundância, com 31 espécies, seguida de Gomphidae com duas espécies (Tab. 1). O ponto onde se coletou mais espécies foi Igatú nas coordenadas $12^{\circ} 53^{\prime} 54^{\prime}$ ' S $41^{\circ} 19^{\prime} 01^{\prime}$ ' O, com 15 espécies, divididas em oito gêneros e duas famílias. Foram coletadas apenas em Mucugê 12 espécies nas coordenadas geográficas 
$12^{\circ} 59^{\prime} 33^{\prime}$ 'S $41^{\circ} 20^{\prime} 30^{\prime}$ O, pertencentes a nove gêneros e uma família. Seis espécies pertencentes a cinco gêneros e uma família, foram coletadas em ambos os pontos. Essa pequena diferença notada na quantidade e ocorrência de espécies entre as áreas de estudo, provavelmente deve-se ao fato de que as coletas foram realizadas durante apenas um ano em diferentes estações que apresentaram condições climáticas distintas. Para testar tal hipótese outras coletas deveriam ser realizadas durante todo o ano em apenas uma área por vez, a partir daí os resultados seriam comparáveis no sentido da distribuição geográfica das espécies.

\begin{tabular}{|c|c|c|c|c|c|}
\hline \multirow{2}{*}{$\begin{array}{l}\text { Subordem } \\
\text { Anisóptera }\end{array}$} & \multirow{2}{*}{$\begin{array}{l}\text { Família } \\
\text { Libellulinae }\end{array}$} & & Espécie & Mucugê & Igatú \\
\hline & & 1842) & Brechmohoga nubecula (Rambur, & 2 machos & \\
\hline & & & Diastatops obscura (Fabricius, 1775) & 2 fêmeas & \\
\hline & & & Dythemis multipunctata Kirby, 1894 & $\begin{array}{l}1 \text { macho e } 1 \\
\text { fêmea }\end{array}$ & 2 machos \\
\hline & & & Dythemis nigrecens Calvert 1899 & & 1 macho \\
\hline & & & Dythemis sp. & & 3 machos \\
\hline & & 1898) & Elasmothemis constricta (Calvert, & 1 macho & \\
\hline & & & Elasmothemis williamsoni (Ris, 1919) & & 3 machos \\
\hline & & & Erythemis attala (Selys in Sagra, 1857) & & 4 machos \\
\hline & & & Erythemis sp. & & $\begin{array}{l}1 \text { macho } \\
1 \text { fêmea }\end{array}$ \\
\hline & & & Erythrodiplax acantha Borror, 1942 & 16 machos & 2 machos \\
\hline & & & Erythrodiplax fervida (Erichson, 1848) & & 4 machos \\
\hline & & & Erythrodiplax fusca (Rambur, 1842) & 16 machos & 14 machos \\
\hline & & & Erythrodiplax Latimaculata Ris, 1911 & 5 machos & 3 machos \\
\hline & & 1839) & Erythrodiplax ochracea (Burmeister, & & 3 machos \\
\hline & & & Erythrodiplax sp. & & 57 machos \\
\hline & & 1757) & Erythrodiplax umbrata (Linnaeus, & $\begin{array}{l}8 \text { machos e } \\
1 \text { fêmea }\end{array}$ & \\
\hline & & 1909 & Gynothemis venipunctata, Calvert, & $\begin{array}{l}2 \text { machos e } \\
2 \text { fêmeas }\end{array}$ & \\
\hline & & & Idiataphe amazonica (Kirby, 1889) & & \\
\hline & & & & 1 macho & \\
\hline & & & Idiataphe longipes (Hagen, 1861) & 4 machos & 1 macho \\
\hline & & & Macrothemis delia Ris 1913 & & 1 fêmea \\
\hline & & & Macrothemis imitans Karsch, 1890 & $\begin{array}{l}14 \text { machos } \\
\text { e } 3 \text { fêmeas }\end{array}$ & \\
\hline & & & Macrothemis sp. & & $\begin{array}{l}2 \text { machos } \\
1 \text { fêmea }\end{array}$ \\
\hline & & 1857) & Miathyria marcella (Selys in Sagra, & & 2 machos \\
\hline & & & Miathyria simplex (Rambur, 1842) & 1 fêmea & \\
\hline & & & Miathyria sp. & & 4 machos \\
\hline & & & Micrathyria atra (Martin, 1897) & 3 machos & \\
\hline & & & Orthemis discolor (Burmeister, 1839) & & 2 machos \\
\hline & & & Pantala flavensces (Fabricius, 1798) & $\begin{array}{l}1 \text { macho e } 1 \\
\text { fêmea }\end{array}$ & 7 machos \\
\hline & & & Tramea cophysa, Hagen 1867 & 5 machos & \\
\hline & & & Tramea calvert Muttkwoski, 1910 & 1 macho & \\
\hline & & & Zenithoptera lanei Santos, 1941 & $\begin{array}{l}14 \text { machos } \\
\text { e } 1 \text { fêmea }\end{array}$ & \\
\hline
\end{tabular}




\begin{tabular}{lcc}
\hline Gomphidae & Progomphus basalis Belle 1994 & 1 macho \\
\hline & Progomphus complicatus (Selys, 1854) & 1 macho \\
\hline & $\mathbf{1 2 0}$ & Espécimes \\
& espécimes & $\mathbf{1 0 6}$ \\
\hline
\end{tabular}

Total 226 espécimes

Desta subordem são conhecidas quatro famílias para o Brasil, para o semiárido foram registradas 21 espécies (Carvalho \& Bravo, 2014) e para a Bahia 16 espécies de Anisoptera (Pinto AP 2017). Para a Chapada Diamantina Carvalho \& Bravo (2017), em um resumo expandido de congresso, listaram oito espécies de Anisoptera, Diastatops obscura (Fabricius, 1775), Erythrodiplax fusca (Rambur, 1842), Erythrodiplax abjecta (Rambur, 1842), Erythrodiplax umbrata (Linnaeus, 1758), Miathyria marcella (Selys in Sagra, 1857), Micrathyria hesperis Ris,1911, Pantala flavescens (Fabricius, 1798) e Perithemis mooma Kirby, 1889. Os autores não especificaram o local de coleta.

Entre as espécies citadas no trabalho de Carvalho \& Bravo, cinco foram também listadas no presente trabalho, Diastatops obscura (Fabricius, 1775), Erythrodiplax fusca (Rambur, 1842), Erythrodiplax umbrata (Linnaeus, 1758), Miathyria marcella (Selys in Sagra, 1857) e Pantala flavescens (Fabricius, 1798). Deste modo as outras 28 espécies aqui listadas são novos registros para a Chapada Diamantina.

\section{- DESCRIÇÃO DA TERMINÁLIA MASCULINA DE ERYTHRODIPLAX ACANTHA BORROR, 1942}

A seguinte descrição foi realizada a partir do estudo de um espécime macho da espécie Erythrodiplax acantha, coletado no Parque Sempre Viva em Mucugê. A terminália masculina dos Odonatos é singular, já que é composta por duas partes, uma anterior onde fica a fossa genital composta pela lâmina anterior, hamulas, lóbulos genitais e estrutura copulatória (vesica espermática) e uma posterior na porção distal do abdômen incluindo elementos dos segmentos nove e 10, o epiprocto, e os cercos, que são estruturas especializadas em segurar a fêmea pelo pronoto durante a cópula, esse encaixe é particular para cada espécie. Os apêndices anais superiores (cercos) na imagem designados como As em vista lateral com formato mais ou menos reto, sem apresentar a porção distal voltada para cima; apêndice anal inferior e mediano (epiprocto), representado nas imagens 1A, B e C designado por Ai com 4/5 do comprimento dos cercos. A lâmina anterior representada nas figuras $2 \mathrm{~A}$ e $2 \mathrm{~B}$, designada por A1 com formato retangular com comprimento curto e largura um pouco maior que o comprimento. Hâmula anterior (A2) com formato bífido e ramo interno menor que o ramo externo. O segmento distal da vesica espermática (A3) longo e cilíndrico com um processo distal truncado. Lóbulo genital (A4), em vista lateral, esclerizado e com formato quadrado com ângulos arredondados.
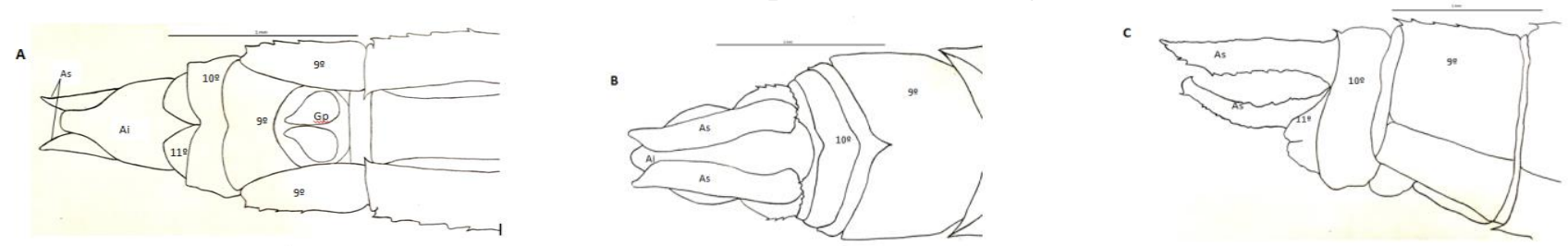

Fig. 01A, 01B e 01C- Parte apical do abdômen do (macho) de Erythrodiplax acantha Borror, 1942 (Anisoptera, Libellulidae), vista pela face ventral (A), dorsal (B) e lateral (C); consideravelmente aumentadas; As, apêndices anais superiores (cercos); Ai, apêndice anal inferior e mediano (epiprocto); Gp, genoporo; $9^{\circ}$, nono segmento ; $10^{\circ}$, décimo segmento; e $11^{\circ}$ segmento. 

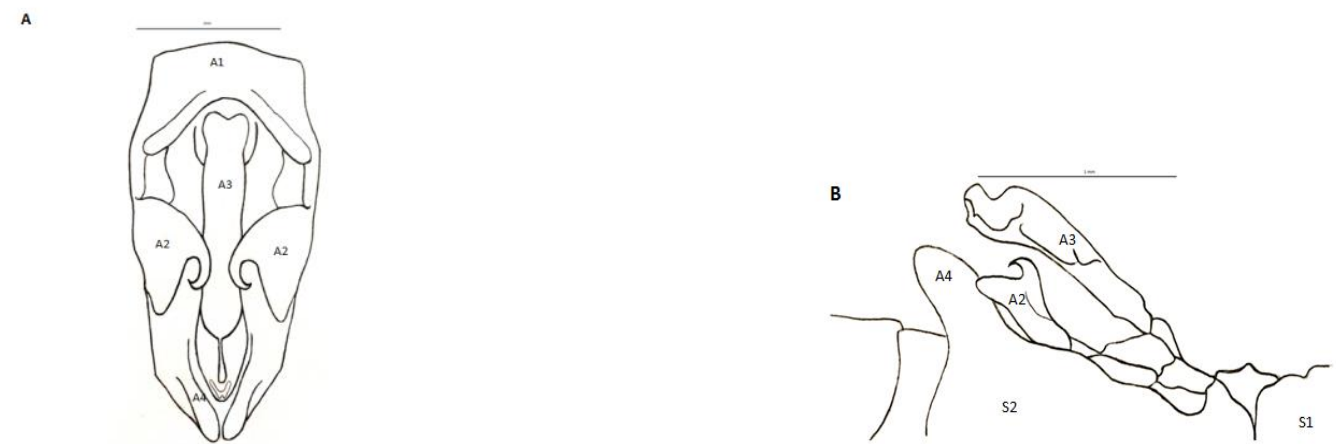

Fig. 02A e 02B - Parte basal do abdômen do macho de Erythrodiplax acantha Borror, 1942 (Anisoptera, Libellulidae), fossa genital masculina vista pela face ventral (A) e lateral (B); consideravelmente aumentadas; A1 Lâmina anterior, A2 Hâmula anterior, A3 pênis, A4 lóbulo genital; S1 primeiro segmento do abdômen, S2 segundo segmento do abdômen.

\section{CONSIDERAÇÕES FINAIS}

O considerável número de exemplares coletados em detrimento da quantidade relativamente baixa de coletas indica que a odonatofauna desta região é abundante. Vinte e oito entre as 33 espécies listadas representam novos registros para a Chapada Diamantina. Esta é uma localidade muito rica em fauna e flora, e pouco estudada no que diz respeito à fauna de Odonatas, isto significa grande potencial para estudo e possíveis espécies novas. Futuras coletas trariam conclusões mais concretas sobre hipóteses sobre distribuição geográfica das espécies levantadas aqui e conhecimento mais aprofundado sobre este local.

\section{REFERÊNCIAS}

- CARVALHO, J. \& BRAVO, F. 2014. Capítulo 6.Odonata do semiárido. In: Bravo, F. \& Calor, A. Artrópodes do semiárido: Biodiversidade e conservação. Print Mídia. Feira de Santana. pp. 83-90.

- CARVALHO, J. \& BRAVO, F. 2017. Lista de espécies de odonata (insecta) da chapada diamantina depositados na coleção entomológica do museu de zoologia da universidade estadual de feira de santana (mzfs. http://www.xviiisemic.esy.es/resumos/i/56790.pdf acessado em $\underline{28 / 07 / 2017}$

- COSTA J.M.; SANTOS, T.C. \& OLDRINI, B.B.; 2012. Odonata. p. 245-256. Insetos do Brasil: Diversidade e taxonomia. Ribeirão Preto: Holos Editora, 810p.

- FUNCH RR. 1982. Chapada Diamantina: uma reserva natural. Salvador: Bureau - GARRISON, R.W., N. VON ELLENRIEDER AND J.A. LOUTON. 2006. Dragonfly genera of the New World: An illustrated and annotated key to the Anisoptera. Baltimore: The Johns Hopkins University Press. 368 p.

- LENCIONI, F. A. A. Damselflies of Brazil 1: Coenagrionidae families: An Ilustrated Identification Guide, 2006. São Paulo, All Print Editora.

-LAND, M. F., 1997. The Resolution of Insect Compound Eyes. Israel Journal of Plant Sciences 45: 79-91.

-Pinto AP 2017. Odonata in Catálogo Taxonômico da Fauna do Brasil. PNUD. Disponível em: 〈http://fauna.jbrj.gov.br/fauna/faunadobrasil/171>. Acesso em: 29 Jul. 2017

- TILLYARD, R.,FRAZER, F.C., 1938. A reclassification of the order Odonata. Australian Zoologist 9: 125-169, 195-221, 359-396. 